\title{
The model of measuring the subjective well-being of a senior age group
}

\author{
Lubov Ivankina $^{1, a}$, Elena Klemasheva ${ }^{1}$, and Yuliya Zeremskaya ${ }^{1}$ \\ ${ }^{1}$ Tomsk Polytechnic University, 634050 Lenin Avenue, 30, Tomsk, Russia
}

\begin{abstract}
The model of measuring the subjective well-being of a senior age group of population built on a reflective base is proved. The model methodology is based on the theory of needs, daily practices, system and life words of individual existence, and it allows defining measured parameters of subjective well-being recorded by the emotional involvement in main spheres of life. The goal of the paper is to justify the model content and to identify key indicators of the subjective significant indices of senior well-being. The objective of the study is to identify factors influencing the level of the subjective well-being of senior population. The study of the problem involves an explication method and a hermeneutical approach used to clarify the basic concepts of the research. Due to theoretical analysis, it is concluded that the subjective well-being is interpreted as an integral, relatively stable individual emotional response to the impact of the social environment and conditions of his/ her life. It is a result of human understanding and experiencing the meanings and significance of different aspects of human life, evolved from the conditions of human existence, which define the satisfaction degree of his/her needs, life opportunities, self-assertion, selfrealization, and actions that are taken to get benefits.
\end{abstract}

\section{Introduction}

The key points of researching the senior population's well-being problem are studies based not only on objective indicators, but also on subjective expectations and preferences; the aggregation of the subjective indicators allows getting a complete picture of reality through the attitudes to what is happening. The research value of the subjective well-being grounds of senior population is significant because it refers to productive strategies for understanding the impacts of macro processes on life quality.

The subjective well-being of elderly population is fixed in adapting to changing of life conditions, in ability to self-service, in continuing to be individuals and in improving the emotional state. Subjective well-being reflects a generalized estimation of a personal life made by an elderly person. The elderly estimate their life from birth to the present moment and also predict their future. The more a person is focused on the future, the more $\mathrm{s} /$ he remains active and thinks in terms of prospects; $\mathrm{s} / \mathrm{he}$ does not worry about the imminent end of life.

Therefore, the problem of optimal conditions in senior population's lives, indicators of well-being and life quality are a promising and popular area of research. Accordingly, it is important to develop a system of indicators allowing the estimation of an individual

\footnotetext{
$\overline{{ }^{a} \text { Corresponding author: ivankina@ }}$ tpu.ru
}

quality of life and subjective well-being in its different aspects for the elderly.

To study the indicators of subjective well-being indices it is necessary to design the model of subjective well-being of senior population and the operational system of indicators used for its measuring.

\section{Methodology of the model content used for measuring the subjective well-being of senior population}

An important stage in the development of the methodology, used for measuring well-being, is that the majority of scientists (especially economists) recognize that well-being is a subjective concept. Subjective estimation is considered as the best tool for measuring well-being, first, as an economic one.

The growing interest in the problem of subjective well-being was marked after a world financial crisis in 2008-2010. In 2009, the Commission's report on measuring economic development and social progress focused on the reduction of traditional approaches to measuring economic and social gains on a national scale based on quantitative indicators of income and consumption. J. Stiglitz, A. Sen, J. Fitoussi recommended to shift the focus from economy performance rating to individual and society well-being 
rating, offering an alternative method of measuring wellbeing as a complex of objective indicators and subjective estimation [1].

The approaches to the measurement of subjective well-being have been described in many scientific papers [2], [3], [4], [5]. International assessment indicators and ratings of the elderly well-being, their comparative characteristics, their advantages and disadvantages are presented in scientific papers [6], [7].

Numerous studies devoted to the problem of the well-being of senior population show that subjective well-being can be characterized as an objective social phenomenon determined by daily living conditions in which people satisfy their needs and realize vital plans and social expectations.

The methodology of the proposed model is based on the concept of everyday practices, because individual daily routine as a complete system includes reactions on everyday life, structuring social reality through the differences due to individual's preferences. Appeal to the practices of everyday life reveals what individual needs should be satisfied, what they are expressed in and what institutional forms of their satisfaction are.

The daily activities of seniors are considered as activities of daily life including the solution of simple tasks such as self-service, maintenance of an active, healthy and self-sufficient life. The most important tasks are housekeeping, mobility, freedom of movement, shopping, walking, cooking and eating, money transactions, medication taking, climbing the stairs, public transports taking and so on.

The principle of the system determination of the theory of psychological systems suggested by V.E. Klochko considers the multidimensional human world as a complete psychological system in the unity with objective world in its prolongation in the mastered part of the world that has meaning and value for a person [8]. A system complex is a number of different objects and systems interacted together. Conspicuously, the key accent is put on differences of objects and their interaction needed for forming a certain unity that corresponds to well-being as an entire system of interrelated objective and subjective processes.

Subjective well-being involves the unity of vital individual experiences as well as the comparison of individual life circumstances with the social norms and values. This allows distinguishing two types of benefits: a normative benefit as a minimum achieved with the help of the complete satisfaction of basic needs and having a universal character; and a eudemonic benefit as a maximum achieved with the help of achievements of a personally meaningful goal and realization of individual existential projects.

External factors of well-being (material, social, environmental benefits and others) in the form of subjective assessments influence the level of subjective well-being as well as personal individual characteristics, which are internal factors of one's well-being.

Subjective well-being is expressed by individual's attitudes to various aspects of his/her own life situation such as income, savings, assets, work, and housing. These attitudes are mediated by the system of individual values and objectives and accepted individual well-being standards as well as self-estimation.

Parameters fixing the model of the subjective wellbeing of senior population are organization optimality of living space that is determined by the development level and performance of social institutions, agencies and organizations designed to provide an access to essential goods, to promote the realization of individual's rights, interests and needs, to form and develop individual's vitality.

The well-being of the elderly is closely connected with the satisfaction of needs, as the experience of pleasure is a key element of subjective well-being. A person, especially an elderly one, wants to be healthy, active, able to cope with emerging challenges of the world and achieve personal goals. S/he needs the support and good will of other people.

Methodology for measuring subjective well-being taking into account the motivation allows generalizing the individual motivational orientation and describing a pattern of requirements in general. The components of the senior life quality are the needs of different levels presented in Maslow's concept of motivation [9]. According to this concept, the following subjective indicators are viable for measuring subjective wellbeing:

1) need satisfaction in comfort, good physical health (physical well-being);

2) financial satisfaction (housing, food, vacation and so on), financial stability (material wealth);

3) satisfaction with asocial status and the current state of the society, interpersonal communications in the microsocial environment and so on (social well-being);

4) positive experience of life purpose and the presence of perspective (mental well-being).

Need satisfaction and benefits getting are realized in a certain space-time continuum. The possibility and availability of owning benefits as a structural element of resources are under the influence of external and internal factors. External factors may be considered as the following: providing life resources for basic human need satisfaction, normalization of relations between human beings and others. Internal factors are considered at the individual level and they are subjective experience, evaluation of the well-being level based on internal individual self-awareness.

Thus, life assessment made by an elderly person expresses his/her level of subjective well-being showing superordinate links through the content of emotionally based estimations giving a multidirectional pattern of an individual activity. Subjective well-being as objective and meaningful experience depends on what is the most important and valuable for a person. Mind and emotions play a great role when choosing a resource of consumption [10]. It is reflected in a well-being structure that gets benefits during the process of need satisfaction in objective and subjective contents.

Accordingly, the crucial task is to find indicators for measuring an individual life quality and the elderly's subjective well-being in its various aspects for operational and long-term process management of constructive aging. 
A structural-tiered approach to the study of subjective well-being involves finding the components of well-being and their level of expressiveness.

\section{Indicators of the subjective well-being of senior population}

Well-being indicators are closely connected with the index. The index is an assessment obtained in the process of activity. There are subjective and objective indices that give rise to two main approaches of selecting information: government statistics and opinion polls, showing the data of the subjective perception of objective reality conditions.

An indicator is an index needed to identify the state of well-being and ill-being. Subjective well-being indicators include both objective and subjective indices describing different aspects of well-being according to the individual's experience: physical, emotional, social, material, economic and moral ones. They are marked on the measuring scale from "completely satisfied" to "completely dissatisfied".

The main condition for indicator selection is a direct link between an indicator (an action) and the characteristics that must be found. An indicator may be both characteristics and its state, so indicators and indices can be considered as identical. The best indicator is chosen from the group of indicators characterizing the study object. The measurement refers to one side of the object that is much poorer than its other sides as a unit.

The main components of measuring are indicators. They are subjective well-being indices presented as emotional and cognitive components, valuable aspects of person's relations to different aspects of his/her life and him/herself due to objective life circumstances and his/her personal characteristics.

The directions of well-being measurement depend on the well-being model that is based on its definition. Due to this study, the elderly in their well-being depend on the satisfaction that is a consequence of needs satisfaction. Thus, the construction of subjective wellbeing indicators requires the identification of senior population's feelings, means and recourses needed for basic needs satisfaction.

Several attempts to make a full list of human needs in relation to existing benefits have been undertaken. The word "well-being" has a special meaning. It is understood as a thing that provides fortune, prosperity and needs satisfaction [11]. Well-being is a material or immaterial substrate for individual needs satisfaction. They are not only material objects or services, but abstract, social and psychological phenomena such as love, prestige and so on. This approach is used in the works of H. Murray [12], A. Maslow [9], M. Rokeach [13], J. Sheth [14]. The implementation of the value approach in identifying significant needs allows determining priority directions for improving the elderly's life quality for a definite period.

The well-being indicators of senior population are grouped according to the areas of well-being manifestation and include the following significant values:

1) Health (physical need to avoid physical damage);

2) Communication with relatives, friends (protection needs);

3) State concern (security, protection, respect and support needs);

4) Material wealth (security need);

5) An ability to be active and operate independently (self-actualization need, autonomy need);

6) Availability of accommodation (physical need);

7) Availability of property ( security need);

8) Continuation of professional activity, employment (physical need, security need, selfactualization need);

9) Participation in public life (need in recognition, need in assistance and support);

10) Leisure activities (need to feel and experience sensations).

Subjective well-being indicators should be connected with benefits that can be recorded objectively or be accepted facts. Before measuring well-being, it should be, first of all, identified; it means that indicators should be found to refer processes and phenomena to wellbeing.

Analyzing factors that influence subjective wellbeing, researches identify different determinants [15]. In the works of foreign researchers on the problem of senior population's well-being [16], [17], [18], [19], the changes in the experience of the subjective well-being by the elderly, its dependence on social factors, the links with personal characteristics and lifestyle are described. K. Musdybaev proved the practicability of correlation of moods, feelings of happiness, life satisfaction, satisfaction with a life status and financial position, feelings of tiredness and unworthiness with subjective well-being indicators [20].

It is possible to note the complex nature of objective and subjective living conditions affecting the subjective well-being of an individual [21]. O.V. Krasnova and A.G. Liders consider that the objective factors affecting subjective well-being are a state of health, income, employment and work, housing facilities, social relations, education, leisure activities. The subjective factors include personality traits such as extraversion and introversion, neuroticism, self-esteem, level of calmness under pressure, self-control, a pattern of thoughts optimism, belief and so on; its motivational structure [21].

The components of the elderly's subjective wellbeing are emotional well-being (fixed emotional wellbeing: anxiety, stress, depression, anger, exhaustion, vivacity, optimism, positive affect, negative affect); selfperception (self-esteem, self-respect, self-identity, body image, a sense of competence, physical fitness); physical well-being and life satisfaction.

Subjective well-being indicators show the emotional life satisfaction and estimate the internal state of a person (health assessment, social optimism, basic values), satisfaction with living conditions (family 
wealth assessment, material well-being assessment, satisfaction with living conditions and society position, personal perspectives), assessment of environmental conditions (social security, social climate in the place of residence and etc.), assessment of emotional experiences (assessment of anxiety level, feelings of loneliness and happiness).

Indicators identification can be guaranteed based on the definite methods. The problem of subjective indicators is connected with questions placed in questionnaires and interviews. It is actual because the quality of questions influences the results of investigation.

\section{Conclusion}

The approach for measuring the subjective well-being of senior population due to everyday practices allows presenting significant indicators such as life satisfaction, satisfaction with a present situation and perception of the future. The choice of these indicators is possible because of the model development that presents a simplified model of reality (a model of everyday life practices including a person). Due to this approach, it is assumed that the study of motivational orientations of the elderly is possible through making a list of needs and matching them with existing benefits. It helps to identify the priority needs and the level of their satisfaction. The comparative analysis along with other parameters of subjective well-being (life satisfaction, the happiness level in the past six months, the presence of prospects and expectations connected with the future and so on) shows a real situation of the subjective mood and the well-being of senior population.

\section{Acknowledgment}

This work was carried out at Tomsk Polytechnic University, Tomsk, Russia, and financially supported by the Ministry of Education and Science of the Russian Federation (Project N 14.Z50.31.0029 'Assessment and improvement of social, economic, and emotional welfare of senior citizens').

\section{References}

1. J. Stiglitz, A. Sen, J.P. Fitoussi, The measurement of economic performance and social progress revisited: reflections and overview. Doc. de Travail de l'OFCE. OFCE (2009) Retrieved from: http://www.stiglitz-senfitoussi.fr/documents/overview-eng.pdf

2. E. Diener, Subjective well-being. Social Indicators Research: The Science of Wellbeing. V. 95 (2009)

3. J.F. Helliwell, C.P. Barrington-leigh, Viewpoint: measuring and understanding subjective well-being. Can. J. of Econ. (2010) Retrieved from: http://onlinelibrary.wiley.com/doi/10.1111/j.1540$\underline{5982.2010 .01592 . x / a b s t r a c t}$
4. D. Kahneman, A.B. Krueger, Developments in the measurement of subjective well-being. J. of Econ. Pers (2006) Retrieved from: https://www.princeton.edu/ kahneman/docs/Publica tions/Development_DK_ABK_2006.pdf

5. R. Layard, J. Sachs, World Happiness Report 2013. World Happiness Report (2013). Retrieved from: http://unsdsn.org/wpcontent/uploads/2014/02/WorldHappinessReport201 3 online.pdf

6. A. Sidorenko, A. Zaidi, Active ageing in CIS countries: semantics, challenges, and responses. Cur. Gerontol, and Ger. R. (2013). Retrieved from: http://www.hindawi.com/journals/cggr/2013/261819 I

7. Global AgeWatch Index 2013: Insight report, summary and methodology. Global AgeWatch Index 2014: HelpAge International. Retrieved from: http://www.helpage.org/globalagewatch/reports/global-agewatch-index-2013insight-report-summary-and-methodology

8. V.E. Klochko, Formation of the multidimensional human world as the essence of ontogenesis. Sib. Psychol. J., 8-9 (1998)

9. A. Maslow, Motivation and Personality (2004)

10. S. Freud, The Ego and the Id St. (2006)

11. S.I. Ozhegov, Russian dictionary. (1989)

12. K.S. Hall, G. Lindsey, Murray's personology. Pers. Theor. (1997).

13. M. Rokich, The nature of human values. (1973)

14. J. N. Sheth, A Model of Industrial Buyer Behavior. J. Marketing, 37, 4 (1973) Retrieved from http://www.jstor.org/stable/1250358.

15. G.M.Golovina, T.N. Savchenko, Subjective life quality: approaches, evaluation methods, applied research (2006)

16. J.F. Helliwell, How's life? Combining individual and national variables to explain subjective wellbeing. Econ. Model. 20, 2 (2003)

17. D. Kahneman, A. Deaton, High income improves evaluation of life but not emotional well-being. Psychol, and Cognitive Sci. 107, 38 (2010)

18. R. Cooper, M. Stafford, R. Hardy, A.A. Sayer, Y.Ben-Shlomo, and ect. Physical capability and subsequent positive mental wellbeing in older people: findings from five HALCyon cohorts. Age (Dordr). 36, 1(2014)

19. T. Gilovich, A. Kumar, L. Jampol, A wonderful life: experiential consumption and the pursuit of happiness. J Consum. Psychol. 25, 1 (2015)

20. K. Muzdylbaev, Changes in the life quality of population in the course of economic liberalization. Pre-eminence in bus: domestic and foreign experiences. (2000). Retrieved from http://www.nir.ru/sj/sj/sj1-01muz.html.

21. O.V. Krasnova, A.G. Liders, Social psychology of seniors (2008) 